\title{
Date of Resuscitated Cardiac Arrest
}

National Cancer Institute

\section{Source}

National Cancer Institute. Date of Resuscitated Cardiac Arrest. NCI Thesaurus. Code C91343.

The date of a cardiac arrest event that was reversed, usually by cardio-pulmonary resuscitation and/or defibrillation or cardioversion, or cardiac pacing. 